Araştırma Makalesi / Research Article

\title{
Kıyı Koruma Yapıları için Delihalil Bazalt Seviyelerinin (Doğu Akdeniz) Kullanılabilirliğinin Değerlendirilmesi
}

\author{
Evaluation of Availability of Delihalil Basalt Levels (Eastern Mediterranean) for Rubble Mound \\ Breakwater
}

\begin{abstract}
Ali ÖZVAN' ${ }^{1}$, İsmail Altay ACAR ${ }^{2}$
${ }^{1}$ Yüzüncü Yıl Üniversitesi, Mühendislik-Mimarlık Fakültesi, Jeoloji Mühendisliği Bölümü, VAN

${ }^{2}$ Çukurova Üniversitesi, Mühendislik-Mimarlık Fakültesi, Jeoloji Mühendisliği Bölümü, ADANA
\end{abstract}

$\begin{array}{lll}\text { Geliş (received) } & : & 12 \text { Mayıs (May) } 2015 \\ \text { Düzeltme (revised) } & : & 25 \text { Mayıs (May) } 2015 \\ \text { Kabul (accepted) } & : & \text { 01 Haziran (June) } 2015\end{array}$

\section{Öz}

Kıyı koruma yapıları, kıyı ve limanlar için önemli yapılardan biridir. Kıyıdaki yapıları dalgalardan korumak için genellikle duraylı ve yüksek kalitedeki doğal kayalar bu yapılar için kullanılmaktadır. Bu çalışmada, Yumurtalık (Doğu Akdeniz) bölgesindeki kıyı koruma yapıları için farklı bazalt seviyelerinin kaliteleri birçok laboratuvar deneyi ile değerlendirilmiştir. Çalışma alanında iki farklı tipte bazalt seviyesi gözlenmiştir. Bu seviyeler farklı kaya kalite sınıflama sistemine göre incelenmiştir. Bazaltlar masif ve boşluklu olarak iki gruba ayrılmaktadır. Boşluklu bazaltta yaygın olarak iddingsitleşme gözlenmektedir. Boşluklu bazalt seviyeleri alterasyondan dolayı zayıf kaya malzeme dayanımı göstermektedir. $\mathrm{Bu}$ seviyenin kıyı koruma yapıları için kullanımı önerilmemektedir.

Anahtar Kelimeler: Bazalt, CIRIA, Kıyı koruma, RERS, Yumurtalık.

\begin{abstract}
Rubble mound breakwater is one of the most important structures for shore and harbor. Durable and high quality natural rocks are commonly used to protect coastal engineering structures from the waves. In this study, numerous laboratory tests were performed for the quality assessment of different basalt levels for rubble mound breakwater in the Yumurtalik (Eastern Mediterranean) region in this study. Two different basalt types were observed in study area. These levels were evaluated with different rock quality classification systems. Basalts were grouped into two classes as massive and vesicular. Iddingsite is a product of alteration of olivine minerals, which are commonly observed in the vesicular basalt. Vesicular basalt levels showed poor rock material strength due to alteration. The vesicular basalt levels in the study area should not be used for armourstones.
\end{abstract}

Key Words: Basalt, CIRIA, Shore protection, RERS, Yumurtalı.

A.Özvan

E-Posta: aozvan@yyu.edu.tr 
Özvan, Acar

\section{GİRIŞ}

Liman yapılarında, dalga etkisine karşı koyacak çeşitli boylardaki kaya malzemelerinin performanslarının değerlendirilmesi özellikle kıyı ülkelerinde ön plana çıkmakta olup, ülkemizde de sıcça çalış1lmıştır (Hoş, 1999; Topal ve Acır, 2004; Acır ve Topal, 2005; Sevdinli, 2005; Ac1r ve Kılıç, 2007; Ertaş ve Topal, 2008; Özden ve Topal, 2009). Bu malzemeler çeşitli boy ve kalitede, ekonomik koşullar göz önünde bulundurularak seçilmelidir. Seçilen kayaların kalite ve performanslarının uzun dönemde duraylı kalabilmesi istenmektedir. Taş dolgu koruma yapılarında kullanılacak malzemelerin iç yapılarındaki özelliklerin belirlenmesi, mühendislik yapısının kullanım süresini belirleyen en önemli unsurdur. Kayalar, iç yapılarından dolayı parçalanarak gereken işlevlerini yerine getiremeyebilirler. Böyle bir durumda koruma yapısının tahrip olması sonucunda güvenlik problemleri ve ekonomik kayıplar ortaya çıkmaktadır. Uygun kaya malzemesinin seçiminde, kayacın sağlamlığ 1 , ayrışma derecesi, kaya içerisindeki zayıf zonlar ve kayacın mineralojisi önemli bir rol oynamaktadır.

Deniz yapılarında kullanılacak kaya malzemelerin seçilmesinde renk, yoğunluk, su emme ve gözeneklilik, süreksizliklerin konumu ve ayrışma durumu, mineralojik ve petrografik özellikleri, kayanın dayanımı, blok bütünlüğü, blok şekli, ağırlığı ve boyutu dikkate alınan başlıca özelliklerdir (Fookes ve Poole, 1981; Latham, 1991; Smith, 1999; Latham vd., 1991; Lienhart, 1994; Latham, 1998; Özvan vd., 2011).

$\mathrm{Bu}$ çalışmanın amacı, ülkemizde hızla gelişmekte olan Yumurtalık bölgesinde yapılacak kıyı koruma yapıları için uygun kaya malzemelerinin belirlenmesidir. Bölge sanayi bakımından gelişmekte olan bir konuma sahip olup, BOTAŞ gibi uluslararası tesislerin bulunduğu bir konuma sahiptir (Şekil 1). Bölgede genel olarak kıyı koruma yapılarında bazalt ve kireçtaşı kullanılmaktadır. $\mathrm{Bu}$ amaçla, bölgede yaygın olarak gözlenen, Delihalil volkanına ait farklı yapıdaki bazalt seviyelerinin kaya kalite değerlendirmesi, kaya malzemesinin fiziksel ve mekanik özelliklerine göre incelenmiştir.

\section{JEOLOJI}

Çalışma alanının jeolojisi ve stratigrafisi önceki yıllarda birçok araştırmacı tarafindan farklı başlıklar altında çalışılmış ve yorumlanmıştır (Bilgin ve Ercan, 1981; Kozlu, 1987; Pelen, 1995; Kozlu, 1997; Parlak vd., 1997; Parlak vd., 2000; Yurtmen vd., 2000; Yüce, 2001; Boyraz, 2002; Yurtmen vd., 2002; Robertson vd., 2004; Uysal, 2005). Çalışma alanında stratigrafik konum olarak tabandan tavana doğru Üst Kretase - Alt Miyosen yaşlı Andırın formasyonu, Alt Miyosen Orta Miyosen yaşlı Karataş formasyonu, Üst Miyosen yaşlı Kızıldere formasyonu, Kuvaterner yaşlı Delihalil bazaltı, kaliş ve alüvyon bulunmaktadır (Şekil 2).

$\mathrm{Bu}$ çalışmada incelenen Delihalil bazaltı tanımı Kozlu (1982) tarafindan Delihalil Tepe'den alınarak verilmiştir. Birim, Yumurtalık civarında Gölovası köyü ve İncirli köyünün bulunduğu alanda, Osmaniye'nin kuzeyindeki Cevdetiye köyü çevresinde ve Aslantaş baraj gölü ile Düziçi ilçesi arasındaki bölgede yüzeylenmektedir (Kozlu, 1997). 


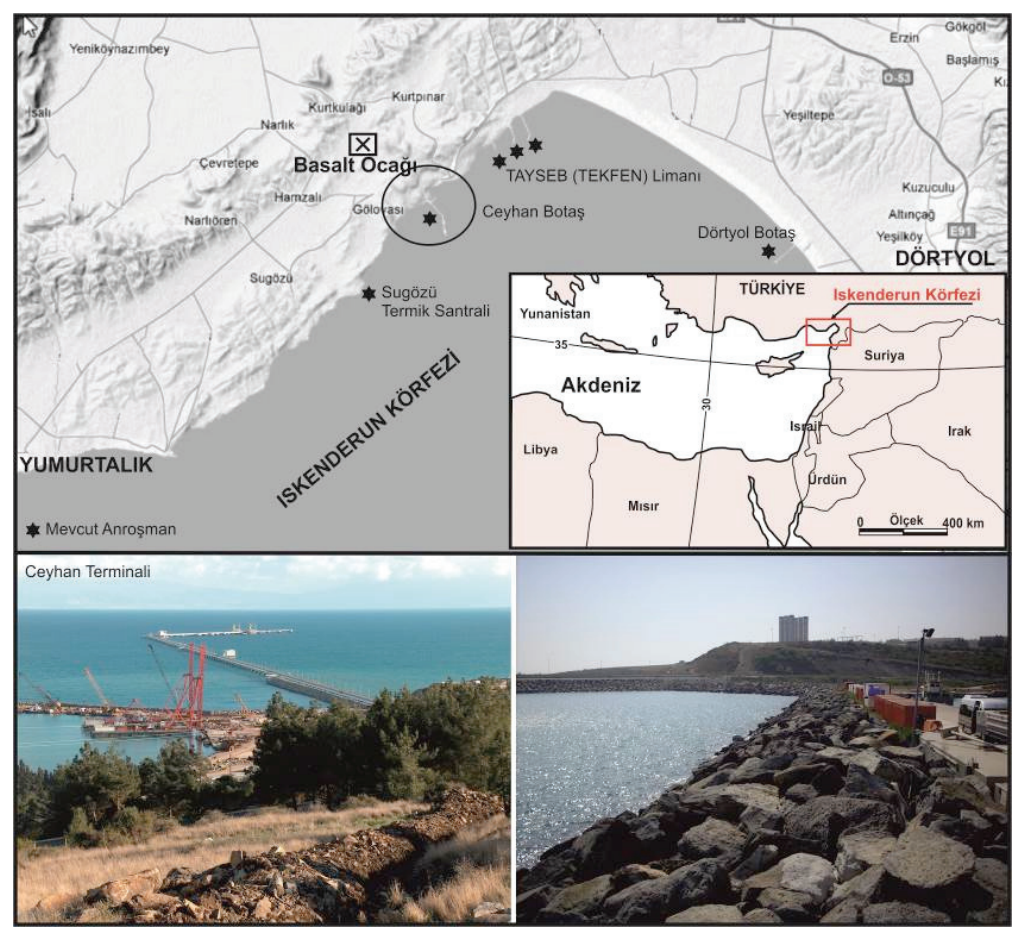

Şekil 1. Çalışma alanına ait yer bulduru haritası.

Figure 1. Location map of the study area.
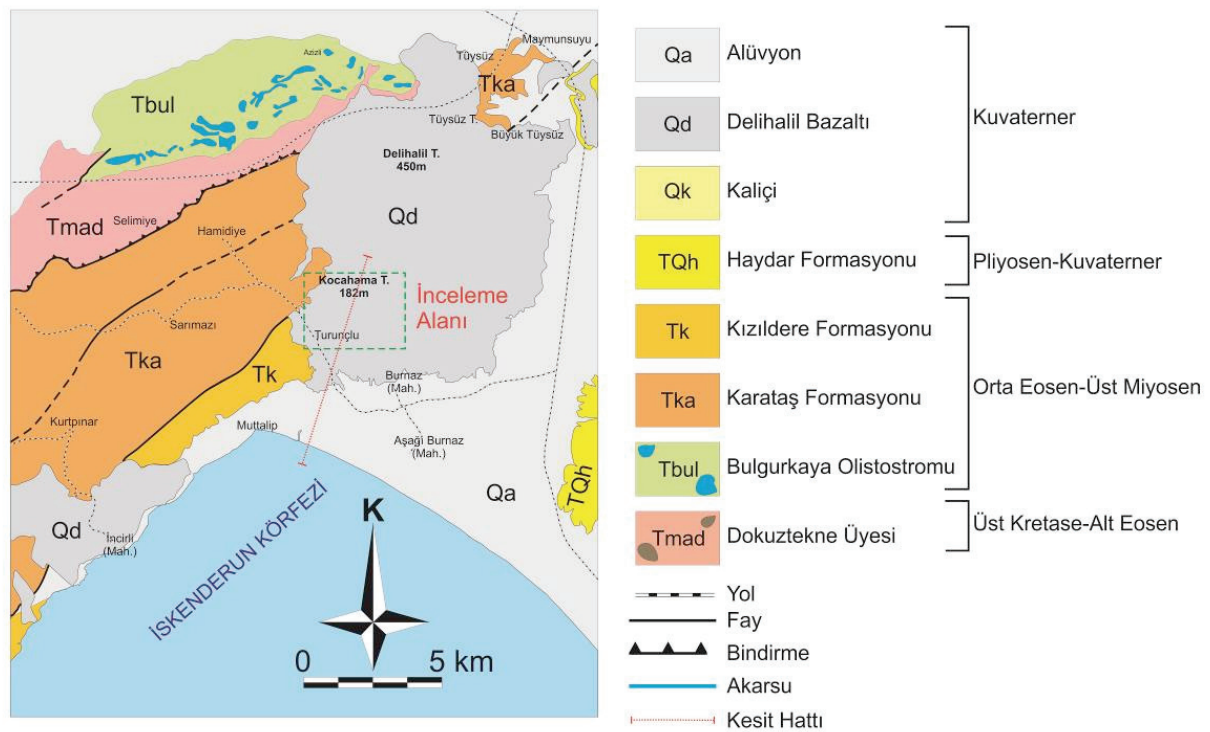

Şekil 2. Çalışma alanının jeoloji haritası (Bilgin vd., 1981; Kozlu, 1997'den değiştirilerek).

Figure 2. Geology map of the study area (modified from Bilgin et al., 1981; Kozlu, 1997). 
Özvan, Acar

Bu bölgedeki bazik bileşimli kayalar genel olarak, piroklastik, gaz boşluklu bazaltlar ve sütunsu bazalt olmak üzere üç tiptedir. Gaz boşluklu seviyeler genelde çalışma alanının güney kesimlerinde bulunan Turunçlu ve Burnaz köyü civarında bulunmaktadır (Şekil 3). Turunçlu ve Burnaz köyü civarında yapılan sondajlı çalışmalarda, yüzeyden yaklaşık $4 \mathrm{~m}$ kalınlığa kadar gaz boşluklu seviye bulunurken bu seviyenin altında masif özellikteki bazaltlara rastlanılmıştır. $\mathrm{Bu}$ seviye devam ettirildiğinde, altında tekrar gaz boşluklu seviyelerin bulunduğu belirlenmiştir. $\mathrm{Bu}$ da bölgedeki volkanik aktivitenin tek seferde gerçekleşmediğini kanitlamaktadir.

\section{Bazalt Seviyelerinin Mühendislik Özellikleri}

$\mathrm{Bu}$ çalışmada öncelikle kıyı koruma yapılarında kullanılabilecek kayalar arazi gözlemleri ile belirlenmiş ve uygun görülen kayalar üzerinde standartlarda belirtilen koşullarda deneyler yapılmıştır. Arazide ve laboratuvarda yapilan değerlendirmede, kayaların litolojik özellikleri ile kaya malzemesinde gözlenen ayrışma ve dayanım özellikleri ISRM (1981), CIRIA/CUR (1991); CIRIA, CUR, CETMEF (2007), BS 932-3 (1997), BS EN 5930:1999, TS EN 13383-1 (2004) ve TS EN 13383-2 (2004) standartlarına göre yorumlanmıştır.

Çalışma alanındaki, koyu grimsi-siyah renkli, soğuma çatlaklı ve yer yer boşluklu olan bazaltların masif seviyelerinin BS 6349-7 (1991), BS 932-3 (1997) ve CIRIA, CUR, CETMEF (2007) standartlarına göre kıyı koruma yapısında kullanılabilirliği değerlendirildiğinde (Özvan vd., 2011), gerek dayanım özellikleri gerekse blok verimi nedeniyle kaya kalitesi mükemmeldir. Kaya kütlesi incelendiğinde, ayrışmanın CIRIA/ CUR (1991), CIRIA, CUR, CETMEF (2007) ve

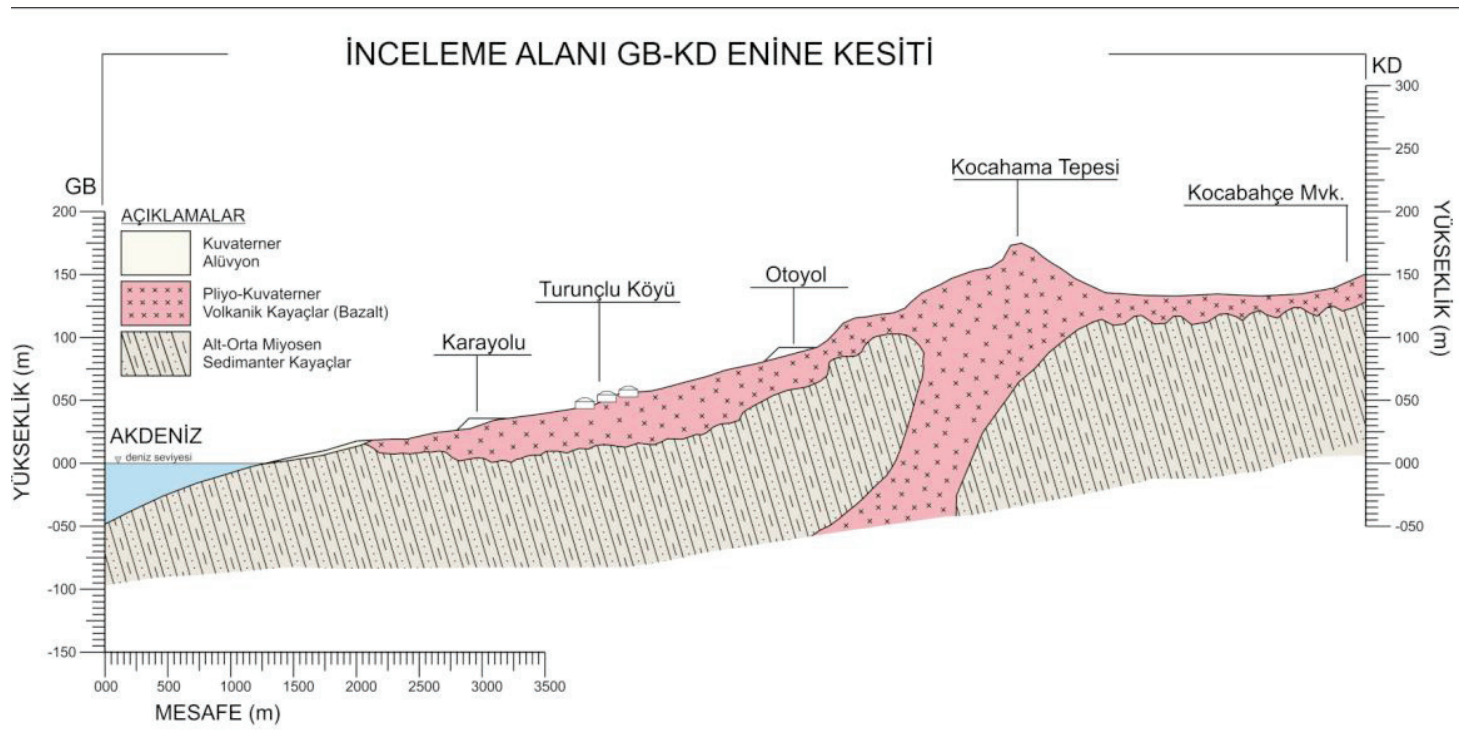

Şekil 3. Çalışma alanının GB-KD hattında enine kesiti.

Figure 3. Cross section of SW-NE line of the study area. 
BS 5930:1999 standartlarına göre, az derecede ayrışma (IB) (ana yüzeyde boyanma şeklinde) - taze ve ayrışmamış (IA) şekillerde olduğu gözlenmiştir. Birim içerisindeki boşluklarda yer yer kalsit dolgu gözlenmektedir. Üst seviyeleri daha boşluklu ve ayrışmış olan bazalt biriminde, derine doğru gidildikçe boşluk yapısı azalmakta ve masif bir yap1 gözlenmektedir.

Çalışma alanındaki bazik bileşimli kayaların petrografik ve kimyasal özellikleri belirlenmiştir. İncelenen ince kesitler içerisinde hakim mineral genellikle plajiyoklasttır. Ek olarak, olivin fenokristalleri ile opak mineraller de gözlenmektedir.

İnceleme alanındaki Kuvaterner yaşlı bazaltlar alkali-subalkali karakterdedir. Olivinli alkali karakterli bazaltlar porfirik dokuya sahip olup bol miktarda gaz boşluğu içermektedir. El örneğinde ayrışmış boşluklu olarak tanımlanan bazaltlarda, olivinler yüksek oranda ayrışma göstererek kırmızımsı kahverengi iddingsite dönüşmüşlerdir (Şekil 4). Olivin kristallerinin etrafında oluşan ayrışma zonu, mineralin yaklaşık tüm alanının \% 15-65'i kadardır (Şekil 4b).

Çalışma alanındaki bazaltlar üzerinde sondaj çalışmaları yapılarak karot örnekler alınmıştır (Şekil 4a). Üzerinde sondaj yapılan bazaltlarda düşeyde üç ayrı seviye gözlenmiştir. Yüzeyden derine doğru gidildiğinde yaklaşık 0 - $3.5 \mathrm{~m}$ arasında gaz boşluklu bir seviye (Üst Seviye), 3.5 - $12 \mathrm{~m}$ arasında masif (Orta Seviye) ve $12 \mathrm{~m}-14 \mathrm{~m}$ arasında tekrar gaz boşluklu ve boşlukların bir kısmının kalsit ile dolgulu olduğu (Alt Seviye) bir seviye belirlenmiştir (Şekil 5).

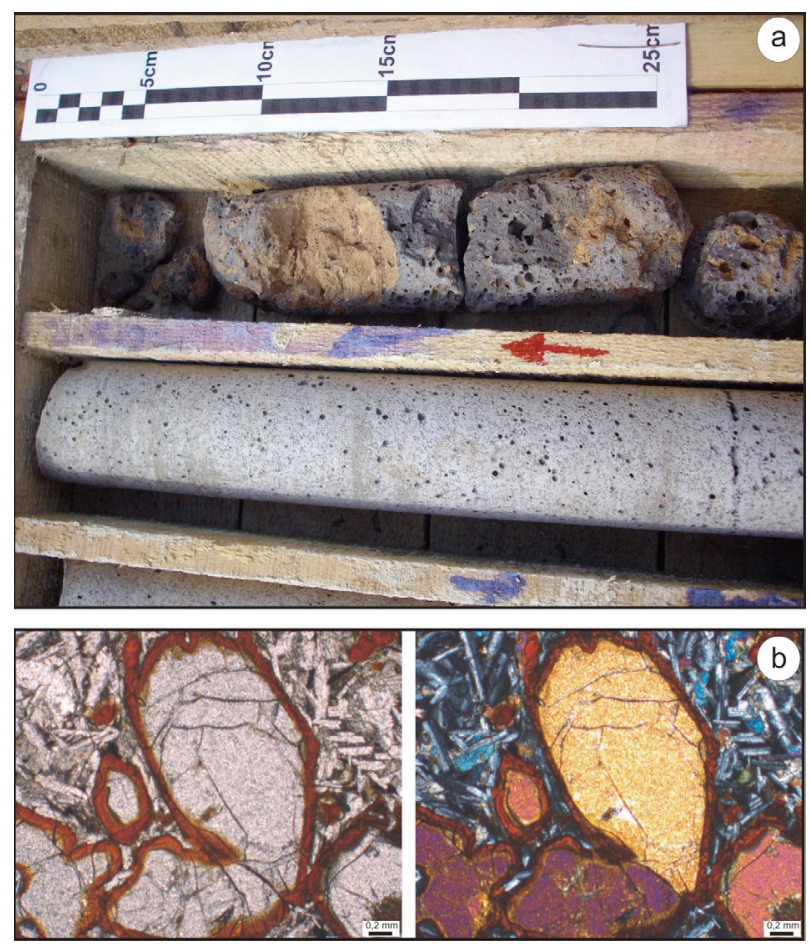

Şekil 4. Çalışma alanındaki ayrışmış bazaltlara ait (a) karot ve (b) ince kesit görüntüleri.

Figure 4. (a) Core samples and (b) thin sections of alterated basalts from the study area. 


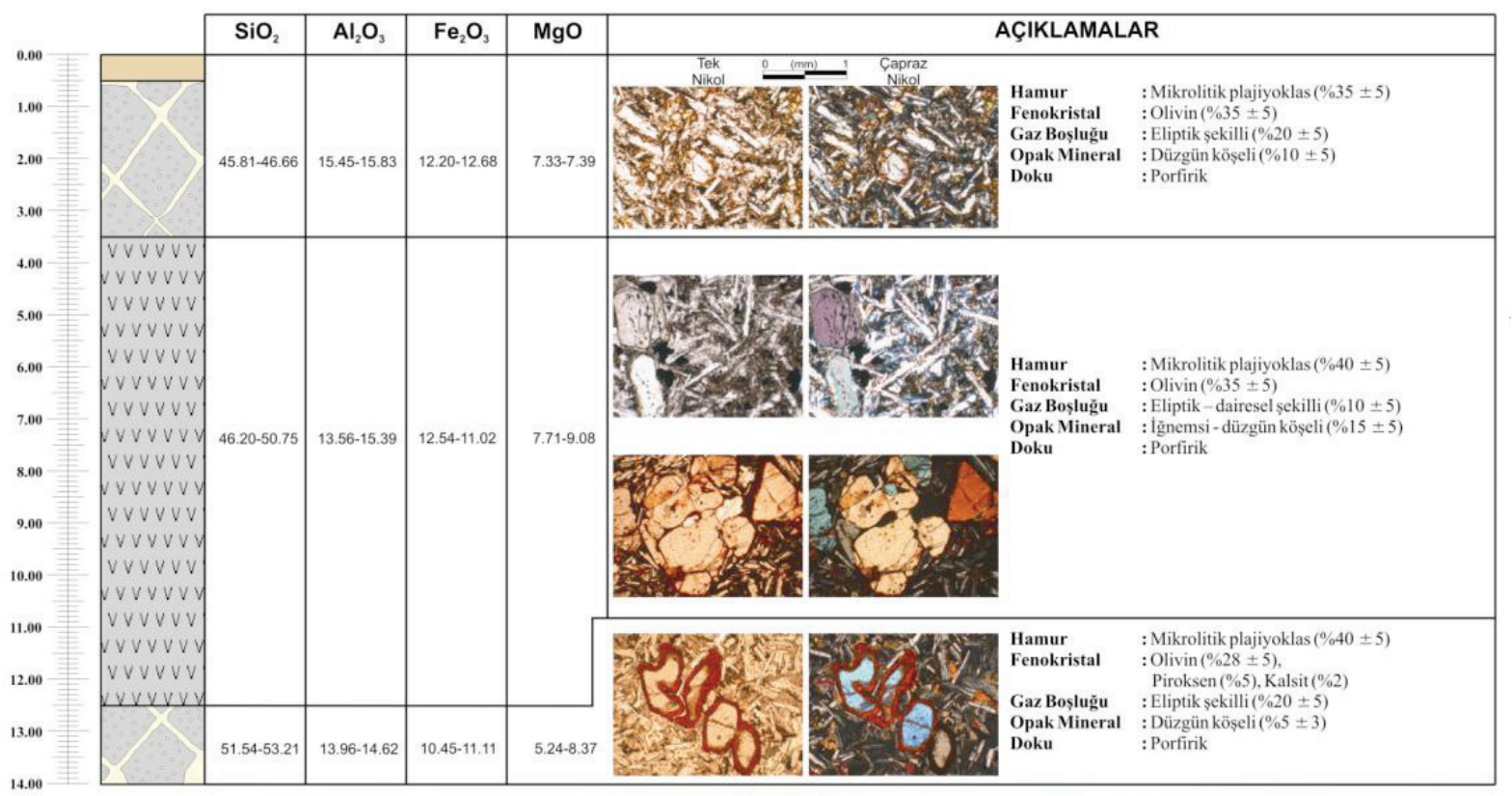

Şekil 5. Farklı derinliklerden alınan bazaltın kimyasal ve mineralojik özellikleri.

Figure 5. Chemical and mineralogical properties of the basalt taken from different depths.

Bazaltların içermiş olduğu ana ve iz elementler ICP-MS (Inductively Coupled Plasma) yöntemiyle ACME (Kanada) laboratuvarında belirlenmiştir. Kimyasal analiz sonuçlarına göre bazaltta; $\mathrm{SiO}_{2} \% 53.21$ - 45.81, $\mathrm{Al}_{2} \mathrm{O}_{3} \% 13.56$ - 15.83, $\mathrm{Fe}_{2} \mathrm{O}_{3} \% 10.45$ - 12.76, $\mathrm{MgO} \% 5.24-9.08, \mathrm{CaO} \% 7.78-10.13, \mathrm{Na}_{2} \mathrm{O}$ $\% 2.93-3.55, \mathrm{~K}_{2} \mathrm{O} \% 0.81-1.09, \mathrm{TiO}_{2} \% 1.67$ $2.32, \mathrm{P}_{2} \mathrm{O}_{5} \% 0.241-0.419, \mathrm{MnO} \% 0.13-0.17$, $\mathrm{Cr}_{2} \mathrm{O}_{3} \% 0.029-0.063$ arasında, ateşte kızdırma kayb1 (LOI) değerleri ise -0.5 ile 1.6 arasında değişmektedir.

\section{Çalışma Alanındaki Bazaltların Jeomekanik Özellikleri}

Çalışma alanında gözlemsel veriler açısından kullanılabilirliği belirlenen bazik bazaltların, boşluklu ve masif seviyeleri üzerinde, fiziksel ve mekanik deneylere ait değişimler incelenmiştir. Deneyler için karot örnekler seçilerek kuru ve doygun haldeki özellikleri belirlenmiştir. Mekanik özelliklerin belirlenmesi amaciyla kullanılan silindirik örnekler NX tip karotiyer kullanılarak alınmış ve standartlarda belirtilen çap/boy (1/2) oranına göre kesilerek hazırlanmıştır. Aşınma deneylerinde kullanılacak farklı boyutlardaki agregalar da deney için istenilen boyutlarda hazırlanmıştır. Deneylerde ISRM (1981), BS EN 932-3 (1997), ASTM-C535 (1989), TS 699 (1987), TS EN 933-9 (2001), TS EN 1367-1 (2001) standartları kullanılmıştır ve sonuçlar (Çizelge 1 ve 2) ISRM (1981) ve CIRIA/CUR (1991)'de belirlenen sinırlar ile karşılaştırılmıştır. 
Çizelge 1. Masif bazalt seviyesine ait deney sonuçları.

Table 1.Experimental test results of massive basalt level.

\begin{tabular}{|c|c|c|c|c|c|}
\hline Özellik & Standart & $\begin{array}{l}\text { Örnek } \\
\text { say1s1 }\end{array}$ & $\begin{array}{c}\text { Kuru } \\
\text { (Ortalama) }\end{array}$ & $\begin{array}{l}\text { Deney } \\
\text { Sonucu }\end{array}$ & $\begin{array}{c}\text { Doygun } \\
\text { (Ortalama) }\end{array}$ \\
\hline Birim hacim ağırlık (kN/m³) & ISRM (1981) & 49 & 26.26 & & 26.56 \\
\hline Efektif Gözeneklilik (\%) & ISRM (1981) & 49 & & 0.72 & \\
\hline Ağırlıkça Su Emme (\%) & ISRM (1981) & 49 & & 1.17 & \\
\hline Hacimce Su Emme (\%) & ISRM (1981) & 49 & & 3.12 & \\
\hline $\begin{array}{l}\text { Metilen Mavisi Emme Değeri } \\
(\mathrm{g} / 100 \mathrm{~g})\end{array}$ & AFNOR (1980) & 2 & & 0.50 & \\
\hline $\begin{array}{l}\text { Nokta Yük Dayanımı İndeksi } \mathrm{I}_{\mathrm{s}(50)} \\
(\mathrm{MPa})\end{array}$ & ISRM (1981) & 10 & 5.63 & & 5.49 \\
\hline Kırılma Tokluğu (MPa.m²) & Bearman (1999) & 10 & 1.18 & & 1.15 \\
\hline $\begin{array}{l}\text { Tek Eksenli Basma Dayanımı } \\
(\mathrm{MPa})\end{array}$ & ISRM (1981) & 16 & 120.03 & & 104.96 \\
\hline Sonik Hız (km/s) & ISRM (1981) & 16 & 4.79 & & 5.11 \\
\hline Los Angeles Aşınma Dayanımı & ASTM-C535 (1989) & 2 & & 15.41 & \\
\hline
\end{tabular}

Çizelge 2. Boşluklu bazalt seviyesine ait deney sonuçları.

Table 2. Experimental test results of vesicular basalt level.

\begin{tabular}{|c|c|c|c|c|c|}
\hline Özellik & Standart & $\begin{array}{l}\text { Örnek } \\
\text { say1s1 }\end{array}$ & $\begin{array}{c}\text { Kuru } \\
\text { (Ortalama) }\end{array}$ & $\begin{array}{l}\text { Deney } \\
\text { Sonucu }\end{array}$ & $\begin{array}{c}\text { Doygun } \\
\text { (Ortalama) }\end{array}$ \\
\hline Birim Hacim Ağırlık (kN/m³) & ISRM (1981) & 15 & 22.91 & & 23.31 \\
\hline Efektif Gözeneklilik (\%) & ISRM (1981) & 15 & & 1.18 & \\
\hline Ağırlıkça Su Emme (\%) & ISRM (1981) & 15 & & 1.76 & \\
\hline Hacimce Su Emme (\%) & ISRM (1981) & 15 & & 4.07 & \\
\hline Metilen Mavisi Emme Değeri (g/100g) & AFNOR (1980) & 2 & & 1.25 & \\
\hline Nokta Yük Dayanımı İndeksi $\mathrm{I}_{\mathrm{s}(50)}(\mathrm{MPa})$ & ISRM (1981) & 10 & 3.78 & & 3.39 \\
\hline Kırılma Tokluğu $\left(\mathrm{MPa}^{\mathrm{m}} \mathrm{m}^{1 / 2}\right)$ & Bearman (1999) & 10 & 0.79 & & 0.71 \\
\hline Tek Eksenli Basma Dayanımı (MPa) & ISRM (1981) & 5 & 73.86 & & 72.05 \\
\hline Sonik Hız $(\mathrm{m} / \mathrm{s})$ & ISRM (1981) & 5 & 4.86 & & 5.05 \\
\hline Los Angeles Aşınma Dayanımı & ASTM-C535 (1989) & 2 & & 41.20 & \\
\hline
\end{tabular}


Özvan, Acar

\section{BAZALTLARIN KALITE VE DAYANIKLILIK DEĞERLENDİRMESİ}

$\mathrm{Bu}$ çalışmada, kaya malzemesinin kalite ve dayanıklılık değerlendirmesi dünyaca kabul görmüş CIRIA, CUR, CETMEF (2007) ve Lienhart (1998) tarafindan önerilen Kaya Mühendisliği Sinıflama Sistemi (RERS) yöntemleri kullanılarak yapılmıştır.

\section{CIRIA/CUR Sinıflaması}

Genelde kı1 koruma yapilarında kullanilacak kaya malzemesinin sinıflandırılmasinda kullanilan en yaygın yöntem, arazi ve laboratuvar verilerinin değerlendirildiği CIRIA/CUR (1991); CIRIA, CUR, CETMEF (2007) siniflama sistemidir. Bu sistemde, kayanın çeşitli özellikleri kullanılarak kaya malzemesinin dayanım özellikleri bir çizelge halinde sunulmaktadır. Çizelge, kaya malzemesinin deneysel özelliklerine göre malzemeyi mükemmel, iyi, orta ve zayıf olmak üzere dört farklı dayanım sınıfına ayırmaktadır. Kaya malzemesinin değerlendirilmesi sırasında kayaya ait yoğunluk, su emme, toplam porozite, metilen mavisi emme değeri, tek eksenli basma dayanımı, sonik hız, nokta yük dayanım indeksi, kırılma tokluğu, Los Angeles aşınma kaybı deneylerine ait sonuçlar kullanılmıştır.

Laboratuvar deneyleri değerlendirildiğinde, masif bazalttın genelde iyi, boşluklu bazalt seviyesinin ise iyi-orta arasında çıktığ belirlenmiştir (Çizelge 3 ve 4). Deney sonuçları arasında kalite sinıflandirmasinda en tutarsiz değerlerin boşluklu bazaltlarda elde edildiğ gözlenmiştir (bkz. Çizelge 4). Bunun en büyük nedeni, bu kaya içerisindeki boşlukların düzensizliği ve ayrışma yoğunludur. İnce kesit araştırmalarında boşluklu bazaltlardaki özellikle olivin mineralinde farklı oranlarda gözlenen ayrışma miktarları bu kayacın deney sonuçları arasında bir uyumsuzluğa neden olmaktadır.

Çalışma alanındaki kayalar üzerinde yapılan arazi ve laboratuvar çalışmaları çerçevesinde incelenen bazaltlar CIRIA, CUR, CETMEF (2007) tarafindan önerilen sınıflandırma sistemine göre değerlendirilmiştir.

Çizelge 3. Masif bazaltın kalite değerlendirmesi (CIRIA, CUR, CETMEF, 2007).

Table 3. Quality assessment of the massive basalt according to (CIRIA, CUR, CETMEF,2007).

\begin{tabular}{lccccc}
\hline \multicolumn{1}{c}{ Deneyler } & Mükemmel & İyi & Orta & Zayıf & Masif Bazalt \\
\hline Yoğunluk $\left(\mathrm{t} / \mathrm{m}^{3}\right)$ & $>2.7$ & $2.5-2.7$ & $2.3-2.5$ & $<2.3$ & $\mathbf{2 . 6 5 6}^{(1)}$ \\
Su Emme (\%) & $<0.5$ & $0.5-2.0$ & $2.0-6.0$ & $>6.0$ & $\mathbf{1 . 1 7}^{(2)}$ \\
Toplam porozite (\%) & $<2$ & $2-6$ & $6-20$ & $>20$ & $\mathbf{3 . 1 0}$ \\
Metilen mavisi emme (gr/100gr) & $<0.4$ & $0.4-0.7$ & $0.7-1.0$ & $>1.0$ & $\mathbf{0 . 5 0}$ \\
Basma Dayanımı (MPa) & $>120$ & $120-80$ & $80-60$ & $<60$ & $\mathbf{1 1 7 . 0 2}^{(3)}$ \\
Sonik Hız (km/sn) & $>6$ & $4.5-6$ & $3-4.5$ & $<3$ & $\mathbf{4 . 8 5}^{(4)}$ \\
Nokta Yük Dayanım İndeksi (MPa) & $>8$ & $4-8$ & $1.5-4$ & $<1.5$ & $\mathbf{5 . 4 9}^{(3)}$ \\
Kırılma Tokluğu (MPa m $\left.{ }^{1 / 2}\right)$ & $>1.7$ & $1.0-1.7$ & $0.6-1.0$ & $<0.6$ & $\mathbf{1 . 1 5}^{(3)}$ \\
Los Angeles aşınma (\%) & $<15$ & $15-25$ & $25-35$ & $>35$ & $\mathbf{1 5 . 4 1}$ \\
\hline
\end{tabular}

(1) Doygun birim hacim ağırlık, (2) Ağırlıkça su emme değeri, (3) Deniz suyuna doygun örnekler, ${ }^{(4)}$ Normal suya doygun örnekler 
Masif bazalt, kaya kalitesi olarak mükemmel-iyi arası değerler vermiş, koruma yapısında koruyucu tabakada, filtre tabakasında ve çekirdek kısmında kullanılabileceği belirlenmiştir (Çizelge 5).
Boşluklu bazaltın ise, koruma yapısının çekirdek kısmında kullanılabileceği, koruyucu tabaka ve filtre tabakasında kullanımının ise olumsuz sonuçlar doğurabileceği belirlenmiştir.

Çizelge 4. Boşluklu bazalttın kalite değerlendirmesi (CIRIA, CUR, CETMEF, 2007)

Table 4. Quality assessment of the vesicular basalt according to (CIRIA, CUR, CETMEF, 2007)

\begin{tabular}{|c|c|c|c|c|c|}
\hline Deneyler & Mükemmel & İyi & Orta & Zayıf & $\begin{array}{c}\text { Boşluklu } \\
\text { Bazalt }\end{array}$ \\
\hline Yoğunluk $\left(\mathrm{t} / \mathrm{m}^{3}\right)$ & $>2.7$ & $2.5-2.7$ & $2.3-2.5$ & $<2.3$ & $2.344^{(1)}$ \\
\hline Su Emme (\%) & $<0.5$ & $0.5-2.0$ & $2.0-6.0$ & $>6.0$ & $1.63^{(2)}$ \\
\hline Toplam porozite (\%) & $<2$ & $2-6$ & $6-20$ & $>20$ & 3.77 \\
\hline Metilen mavisi emme (gr/100gr) & $<0.4$ & $0.4-0.7$ & $0.7-1.0$ & $>1.0$ & 1.25 \\
\hline Basma Dayanımı (MPa) & $>120$ & $120-80$ & $80-60$ & $<60$ & $\mathbf{7 2 . 5 6}^{(3)}$ \\
\hline Sonik Hız (km/sn) & $>6$ & $4.5-6$ & $3-4.5$ & $<3$ & $\mathbf{5 . 0 5}^{(4)}$ \\
\hline Nokta Yük Dayanım İndeksi (MPa) & $>8$ & $4-8$ & $1.5-4$ & $<1.5$ & $3.39^{(3)}$ \\
\hline Kırılma Tokluğu (MPa m²) & $>1.7$ & $1.0-1.7$ & $0.6-1.0$ & $<0.6$ & $0.71^{(3)}$ \\
\hline Los Angeles aşınma (\%) & $<15$ & $15-25$ & $25-35$ & $>35$ & 41.2 \\
\hline
\end{tabular}

(1) Doygun birim hacim ağırlık, ${ }^{(2)}$ Ağırlıkça su emme değeri, ${ }^{(3)}$ Deniz suyuna doygun örnekler, ${ }^{(4)}$ Normal suya doygun örnekler

Çizelge 5. Kıyı koruma yapılarında ayrışmamış kayaların kullanımı ile ilgili genel değerlendirme (CIRIA/CUR (1991); CIRIA, CUR, CETMEF (2007)).

Table 5. Generalized evaluation of unweathered rock in rubble mound breakwaters (CIRIA/CUR (1991); CIRIA, CUR, CETMEF (2007)).

\begin{tabular}{lccc}
\hline \multicolumn{1}{c}{ Deney veya Gözlem } & Koruyucu Tabaka & Filtre Tabakaları & Çekirdek / Dolgu \\
\hline Ayrışma Derecesi & I - II & I - II & I - II \\
Süreksizlik aralığ $(\mathrm{mm})$ & 1.00 & 0.50 & 0.20 \\
RQD (\%) & $80-100$ & $75-100$ & $55-100$ \\
Porozite (\%) & $0-5$ & $0-100$ & $0-10$ \\
Su emme (\%) & $<2.0$ & $<2.5$ & $<3.0$ \\
Tek eksenli basma dayanımı (MPa) & $>100$ & $>100$ & $>50$ \\
Yoğunluk (t/m $\left.{ }^{3}\right)$ & $>2.6$ & $>2.6$ & $>2.0$ \\
Masif bazalt & $\sqrt{ }$ & $\sqrt{ }$ \\
Boşluklu bazalt & & & $\sqrt{ }$ \\
\hline
\end{tabular}


Özvan, Acar

\section{Kaya Mühendisliği Sınıflama Sistemi (RERS)}

Kıyı koruma yapıları (Anroşman) için CIRIA/CUR (1991); CIRIA, CUR, CETMEF (2007) sınıflama sistemi dışında kullanılan bir diğer sistem, Kaya Mühendisliği Sınıflama Sistemi (RERS)' dir. Lienhart (1998) tarafindan önerilen bu sistem koruma taşı olarak kullanılabilecek uygun malzeme kaynağının belirlenmesi ve değerlendirmesindeki işlemleri içerir. $\mathrm{Bu}$ sistemde, bir malzeme ocağındaki kayanın üretim ve test yöntemleri, kayanın taze ve ayrışmış kısımlarının kalitesi incelenmektedir. Malzemenin taşınması ve yerleştirilmesi gibi süreçler de değerlendirilir. Kaya mühendisliği sınıflama sistemi, diğer yöntemlere göre kaynak kaya hakkında daha geniş bir veri aralığını göz önüne almakta ve karşılaştırmaktadır. $\mathrm{Bu}$ yöntemde, araştırmacıların tecrübelerine ve yerinde gözlemlerine bağlı olarak hesaplanan değerler ve o değerlerin içinde kaldığ 1 sınırlar çalışmacılara göre düzenlenebilir (Lienhart, 1998). Bu yöntemin uygulanmasında; jeolojik faktör, üretim faktörleri ve kayanın özellikleri en önemli ölçütlerdir.

Jeolojik ölçütte; litoloji, kaya malzemesinin ayrışma derecesi, süreksizlik koşulları, yeraltısuyu ve bölgesel gerilmeler dikkate alınmaktadır. Üretim yöntemi ölçütünde ise üretim yöntemi, kaya kalitesi, depo ömrü ve blok sağlamlığı değerlendirilmektedir. Bu iki yöntem daha çok sahada mühendisin yapacağ1 gözlemler ile puanlandırılmaktadır. Kaya özelliği ölçütünde ise; petrografi, birim hacim ağırlık, su emme, sonik hız, nokta yük dayanım indeksi, tek eksenli basma dayanımı, Los Angeles aşınma dayanımı gibi deneylerden elde edilen değerler kullanılmaktadır.
Koruma yapısının kaya mühendisliği sınıflama sistemi yapılırken, farklı değişkenler için sebep-etki dereceleri ve bu derecelere ait indeks sayllar belirlenmektedir (Lienhart, 1998). $\mathrm{Bu}$ indeks say1lar kaya malzemesinin durumuna bağlı olarak Lienhart (1998) tarafindan verilen şekilde kullanılmaktadır.

Bazalt seviyelerinin litolojik olarak tanımlanmasında, kayanın masif yapısı ile kil içeriği ve gözenekliliğine bağlı değişimler göz önünde bulundurulmuştur. Boşluklu bazaltın yapısındaki boşluk ve ayrışma yüzeyleri nedeniyle litolojik derecesi orta sınıfta, masif bazaltta ise kayanın yapısının homojenliği nedeniyle litolojik derecesi mükemmel sinıfta değerlendirilmiştir.

Bölgesel gerilmeler ise masif bazalt için kayacın Kuvaterner yaşlı olması ve derine doğru gidildikçe eklemlerin azalması nedeniyle mükemmel olarak derecelendirilmiştir. Boşluklu bazaltlar yüzeye yakın yerlerde genelde sütunsal şekilli olmalarından dolayı orta derecede değerlendirilmiştir.

Ayrışma derecesine göre yapılan değerlendirmede, masif bazaltta ana yüzeyde boyanma şeklinde az derecede ayrışma gözlenmektedir. Boşluklu bazaltta ise, el örneğinde ISRM (1981)'e göre orta derecede ayrışma gözlenmektedir. Ayrışma durumuayrıntılı olarak ince kesitte gözlenmektedir. Boşluklu bazaltlarda gözlenen iddingsitleşme kayadaki en zayıf düzlemleri oluşturmaktadır. Bu nedenle kaya malzemesi masif bazaltta iyi, boşluklu bazaltta orta derecede değerlendirilmiştir.

Çalışma sahasında gözlemsel incelemeler sonucunda yapılan süreksizlik değerlendirmesine göre, boşluklu bazaltta gözlenen prizmatik 
soğuma çatlakları nedeniyle süreksizlik açısından orta sınıfta değerlendirilmiştir. Masif bazalt ise eklem ara uzaklıklarının genelde $50 \mathrm{~cm}$ 'den daha büyük olması nedeniyle iyi kaya kalitesinde değerlendirilmişlerdir.

Üretim yöntemi açısından kayaçlar yorumlandığında, sağlam kayaya patlatma ile ulaşılmaktadır. Üstteki boşluklu seviye sökülerek alttaki masif kayaya geçilmeli ve masif kayada derine doğru kazı yapılarak uygun kaya malzemesi çıkarılmalıdır (Şekil 6). Bu nedenle bazaltlarda üretim yöntemi iyi derecede değerlendirilmiştir.

Stoklamada, boşluklu bazalttın dışındaki seviyeler iyi sınıfta değerlendirilmiştir. Boşluklu bazaltların ise kırılma tokluğu değerleri, gerek taşınma sırasında gerekse stokta yığın halinde bekletilmesi sırasında parçalanmanın olacağını göstermektedir. $\mathrm{Bu}$ nedenle boşluklu bazaltlar orta sınıfta değerlendirilmiştir.
Kaya kütlesinin eklemli yapısına ve kayacın içyapısına bağlı olan blok verebilme özelliği, boşluklu bazaltlardaki boşluk yapısı ve soğuma çatlakları nedeniyle orta, masif bazaltta ise mükemmel sınıfta değerlendirilmiştir.

Petrografik değerlendirmede ise, boşluklu bazaltlar, ince kesitlerinde gözlenen mikroçatlak yoğunluğu ve \% 65'e varan iddingsitleşme nedeniyle orta sınıfta değerlendirilmiştir. Masif bazaltta gözlenen mikroçatlaklar nedeniyle oluşacak zayıflık düzlemlerinin etkisinin az olacağı düşüncesiyle, bu kayaçlar iyi sınıfta değerlendirilmiştir.

Seçilen kaya malzemeleri üzerinde yapılan deneyler sonucunda, nokta yük dayanım indeksi, su emme değerlerine bağlı olarak Lienhart (1998) tarafından önerilen indeks sayılar alınmış ve kaya malzemesinin kalite özellikleri bu deneylere göre derecelendirilmiştir (Çizelge 6 ve 7).

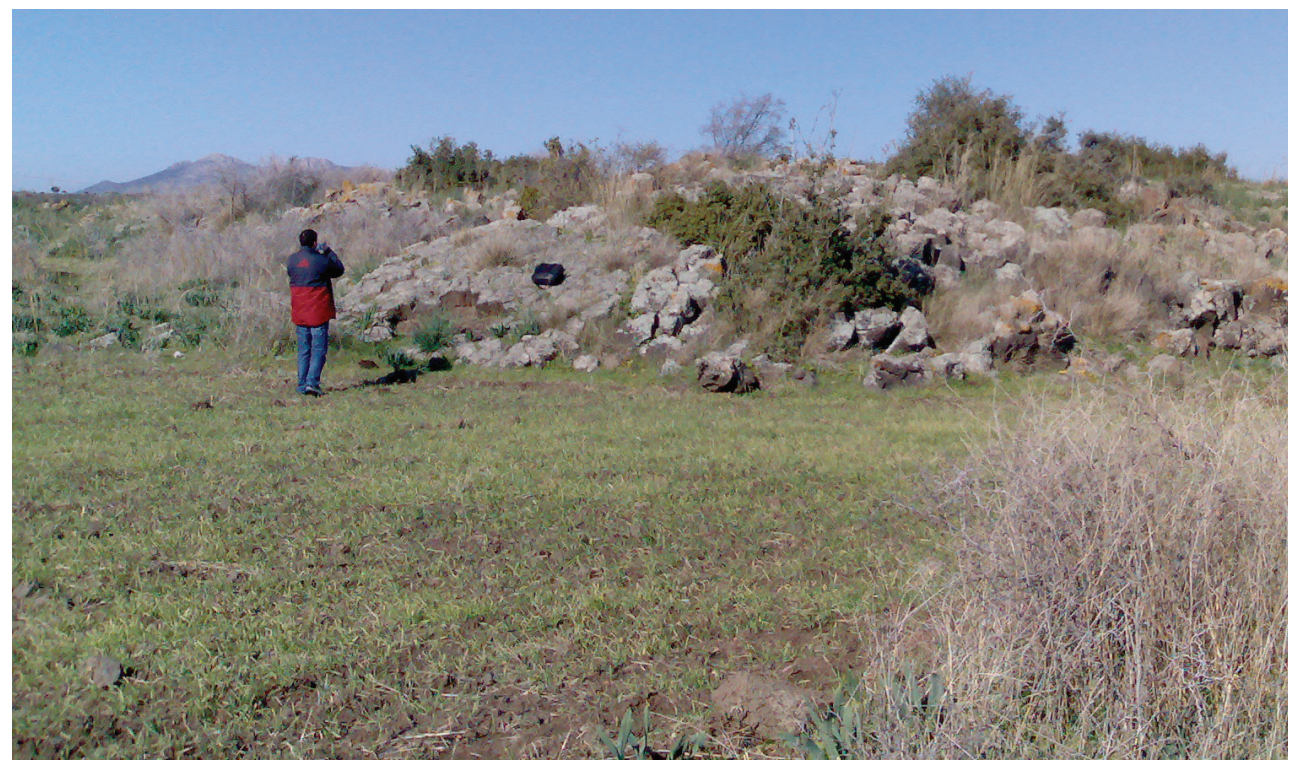

Şekil 6. İnceleme alanındaki bazaltik lavlar.

Figure 6. Basaltic flow from the study area. 
Özvan, Acar

Çizelge 6. Masif bazaltın RERS sistemine göre kalite değerlendirmesi.

Table 6. Quality rating assessment of the massive basalt according to RERS.

$\underline{\text { Kalite Değerlendirmesi }}$

\begin{tabular}{|c|c|c|c|c|c|c|}
\hline & & & & & & \\
\hline Ölçüt Tipi & Ölçüt & 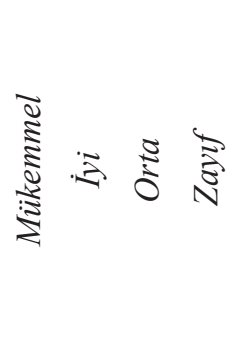 & 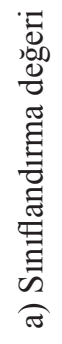 & 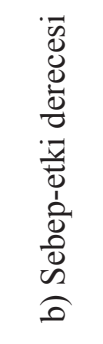 & 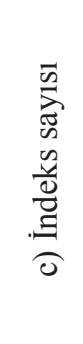 & 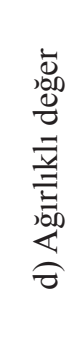 \\
\hline & Litolojik tanımlama & $\sqrt{ }$ & 4 & 11.31 & 0.74 & 2.96 \\
\hline & Bölgesel gerilimler & $\sqrt{ }$ & 4 & 14.14 & 0.93 & 3.72 \\
\hline $\begin{array}{c}\text { Jeolojik } \\
\text { Ölcüt }\end{array}$ & Ayrışma derecesi & $\sqrt{ }$ & 3 & 14.14 & 0.93 & 2.79 \\
\hline & Süreksizlik analizi & $\sqrt{ }$ & 3 & 18.38 & 1.20 & 3.60 \\
\hline & Yeraltı suyu & $\sqrt{ }$ & 4 & 14.14 & 0.93 & 3.72 \\
\hline & Üretim yöntemi & $\sqrt{ }$ & 3 & 15.56 & 1.02 & 3.06 \\
\hline Üretim & Stoklama & $\sqrt{ }$ & 3 & 15.56 & 1.02 & 3.06 \\
\hline Yöntemi & Kaya kalitesi & $\sqrt{ }$ & 4 & 13.43 & 0.88 & 3.52 \\
\hline & Blok bütünlüğü & $\sqrt{ }$ & 4 & 15.56 & 1.02 & 4.08 \\
\hline & Petrografik değerlendirme & $\sqrt{ }$ & 3 & 18.38 & 1.20 & 3.60 \\
\hline $\begin{array}{c}\text { Kaya } \\
\text { Özelliği }\end{array}$ & Nokta yük dayanım indeksi (MPa) & $\sqrt{ }$ & 3 & 16.97 & 1.11 & 3.33 \\
\hline & Su emme $(\%)$ & $\sqrt{ }$ & 3 & 15.56 & 1.02 & 3.06 \\
\hline
\end{tabular}

Ortalama $=15.28 \quad$ Derece $=3.35(\mathbf{I} \mathbf{y i})$ 
Çizelge 7. Boşluklu bazaltın RERS sistemine göre kalite değerlendirmesi.

Table 7. Quality rating assessment of the vesicular basalt according to RERS.

$\underline{\text { Kalite Değerlendirmesi }}$

\begin{tabular}{|c|c|c|c|c|c|c|c|}
\hline & & & & & & & \\
\hline Ölçüt Tipi & Ölçüt & 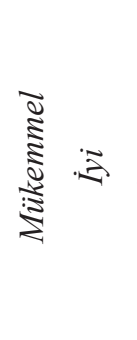 & క & 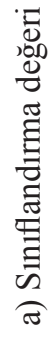 & 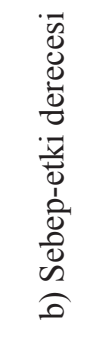 & 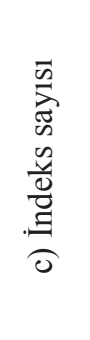 & 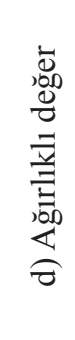 \\
\hline & Litolojik tanımlama & & $\sqrt{ }$ & 2 & 11.31 & 0.74 & 1.48 \\
\hline & Bölgesel gerilimler & $\sqrt{ }$ & & 3 & 14.14 & 0.93 & 2.79 \\
\hline $\begin{array}{c}\text { Jeolojik } \\
\text { Ölcït }\end{array}$ & Ayrışma derecesi & & $\sqrt{ }$ & 2 & 14.14 & 0.93 & 1.86 \\
\hline & Süreksizlik analizi & & $\sqrt{ }$ & 2 & 18.38 & 1.20 & 1.40 \\
\hline & Yeraltı suyu & $\sqrt{ }$ & & 4 & 14.14 & 0.93 & 3.72 \\
\hline & Üretim yöntemi & $\sqrt{ }$ & & 3 & 15.56 & 1.02 & 3.06 \\
\hline Üretim & Stoklama & & $\sqrt{ }$ & 2 & 15.56 & 1.02 & 2.04 \\
\hline Yöntemi & Kaya kalitesi & & $\sqrt{ }$ & 2 & 13.43 & 0.88 & 1.76 \\
\hline & Blok bütünlüğü & & $\sqrt{ }$ & 2 & 15.56 & 1.02 & 2.04 \\
\hline & Petrografik değerlendirme & & $\sqrt{ }$ & 2 & 18.38 & 1.20 & 2.40 \\
\hline $\begin{array}{l}\text { Kaya } \\
\text { Özelliği }\end{array}$ & Nokta yük dayanım indeksi (MPa) & & $\sqrt{ }$ & 2 & 16.97 & 1.11 & 2.22 \\
\hline & Su emme $(\%)$ & $\sqrt{ }$ & & 3 & 15.56 & 1.02 & 3.06 \\
\hline
\end{tabular}

Ortalama $=15.28 \quad$ Derece $=2.45($ Orta $)$ 
Özvan, Acar

\section{SONUÇLAR}

$\mathrm{Bu}$ çalışma kapsamında, Yumurtalık (Doğu Akdeniz) bölgesinde bulunan masif ve boşluklu bazalt seviyelerinin taş dolgu kıyı koruma yapıları için performansları incelenmiştir.

İki farklı bazalt seviyesi için yapılan kaya mühendisliği sınıflama sistemi (RERS) derecesine göre kaya dolgu koruma yapısı olarak kullanılacak malzemelerin kalite puanları, yukarıda belirtilen ölçütler göz önünde bulundurularak hesaplanmıştır. Yapılan değerlendirmelerde masif ve boşluklu bazaltta sirasıyla 3.35 (iyi) ve 2.45 (orta) değerleri elde edilmiştir. $\mathrm{Bu}$ çalışmada ele alınan kayaların laboratuvar ve saha performansları CIRIA, CUR, CETMEF (2007)ve RERS'ye göre kıyasladığında sonuçlar uyumlu çıkmaktadır. Gerek ülkemizde DLH (2007) tarafindan önerilen, gerekse dünya genelinde yaygın olarak kullanılan bu iki standarda göre, çalışma alanında bulunan masif bazalt iyi kalitede, boşluklu bazalt ise orta kalitede çıkmaktadır.

Yumurtalık bölgesindeki kı1 koruma yapılarının birçoğunda bazalt kullanılmaktadır. Bölgedeki bazalt birimlerin ince kesitlerinde özellikle olivin minerallerinin etrafinda alterasyonların olduğu gözlenmiştir. $\mathrm{Bu}$ alterasyonların özellikle boşluklu bazalt seviyelerinde yoğun olduğu ve kayacin performansını düşürdüğü belirlenmiştir. $\mathrm{Bu}$ bazaltların koruyucu ve filtre tabakalarında kullanılması önerilmemektedir. Bu malzemelerin bölgede yapılan limanlarda sık kullanılması nedeniyle limanlarda oluşabilecek muhtemel malzeme yenilmeleri takip edilmeli ve gerekli önlemler alınmalıdır.

\section{KATKI BELİRTME}

$\mathrm{Bu}$ çalışma MMF 2007D2 numaralı proje ile Çukurova Üniversitesi Bilimsel Araştırmalar Proje Başkanlığ (BAP) tarafından desteklenmiştir. Finansal desteği için Çukurova Üniversitesi Bilimsel Araştırmalar Proje Başkanlığı'na teşekkür ederiz. Makalenin değerlendirilmesi aşamasında görüşlerinden faydalandığımız sayın Doç. Dr. İsmail Dinçer'e, Doç. Dr. Mutluhan Akın'a, Yrd. Doç. Dr. Müge Akın'a ve hakemlere teşekkür ederiz.

\section{KAYNAKLAR}

Acır, Ö., Topal, T., 2005. Helaldı (Sinop) dalgakıranında dolgu malzemesi olarak kullanılacak kayaların kalitelerinin belirlenmesi. Mühendislik Jeolojisi Bülteni, 21, 1-17.

Acır, Ö., Kılıç, R., 2007. Samsun Limanı ana (kuzey) mendireği anroşmanlarının duraylılığının incelenmesi. 60. Türkiye Jeoloji Kurultayı, 301-302.

AFNOR (L'Association Francaise de Normalization), 1980. Essai au bleu de methylene, AFNOR 80181. Paris La Defence., 18-592.

ASTM-535, 1989. Standard test method for resistance to degradation of large-size coarse aggregate by abrasion and impact in the Los Angeles Machine. C535, Annual Book of of ASTM Standards, American Society for Testing and Materials, West Conshocken, PA., 285-287.

Bearman, R. A., 1999. The use of the point load test for the rapid estimation of Mode I fracture toughness: International Journal of Rock Mechanics and Mineral Sciences, 36, 257-263. 
Bilgin, Z., Ercan, T., 1981. Ceyhan - Osmaniye yöresindeki kuvaterner bazaltların petrolojisi. Türkiye Jeoloji Kurumu Bülteni, 24, 22-30.

Boyraz, O., 2002. Demirtaş - Sarımazı (Adana - Yumurtalık) arasının tektono-stratigrafisi. Çukurova Üniversitesi Fen Bilimleri Enstitüsü Yüksek Lisans Tezi, 46 s, (yayınlanmamış).

BS 932-3, 1997. Tests for general properties of aggregates. Procedure and terminology for simplified petrographic description. British Standards Institution, London.

BS 5930, 1999. Code of Practice for Site Investigation. British Standards Institution, London.

BS 6349-7, 1991. Maritime structures. Guide to the design and construction of breakwaters. British Standards Institution, London.

BS EN 932-3, 1997. Tests for general properties of aggregates. Procedure and terminology for simplified petrographic description. British Standards Institution, London.

CIRIA/CUR, 1991. Manual on the Use of Rock in Coastal and Shoreline Engineering. CIRIA Special Publication 83, Report:154, London, 607 p.

CIRIA, CUR, CETMEF, 2007. The Rock Manual. The use of rock in hydraulic engineering. 2nd edition. C683, CIRIA, London, 1234 p.

DLH, 2007. Kıyı Yapıları ve Limanlar Malzeme, Yapım, Kontrol ve Bakım Onarım Teknik Esasları. 101 s, Ankara.

Ertaş, B., Topal, T., 2008. Quality and durability assessments of the armourstones for two ruble mound breakwaters (Mersin, Turkey). Environmental Geology, 53, 1235-1247.
Fookes, P. G., Poole, A. B., 1981. Some preliminary considerations on the selection and durability of rock and concrete materials for breakwaters and coastal protection works. Quaternary Journal of Engineering Geology, 14, 97-128.

Hoş, T., 1999. Dalgakıran inşaatlarında kullanılan kireçtaşlarının jeoteknik özellikleri. 52. Türkiye Jeoloji Kurultayı Bildiriler Kitabı, Ankara, 3238.

ISRM (International Society for Rock Mechanics), 1981. Rock characterization, testing and monitoring: ISRM Sugested Methods. E.T. Brown (ed), Pergamon Pres, Oxford, 211 p.

Kozlu, H., 1982. İskenderun baseni jeolojisi ve petrol olanakları. TPAO Rapor no: 1921, Ankara.

Kozlu, H., 1987. Misis-Andırın dolaylarının stratigrafisi ve yapısal evrimi. Türkiye 7. Petrol Kongresi Dergisi. 104 - 116.

Kozlu, H., 1997. Doğu Akdeniz Bölgesinde yeralan Neojen basenlerinin (İskenderun, Misis-And1rın) Tektono-Stratigrafi birimleri ve bunların tektonik gelişimi. Çukurova Üniversitesi Fen Bilimleri Enstitüsü Doktora Tezi, 189 s, (yayınlanmamış).

Latham, J. P., 1991. Degradation model for rock armour in coastal engineering. Quaternary Journal of Engineering Geology , 24, 101-118.

Latham, J.P. ,1998. Assessment and specification of armourstone quality from CIRIA/CUR (1991) to CEN (2000). In: Advances in Aggregates and Armourstone Evaluation. The Geological Society, Engineering Geology Special Publication No.13, 65-85. 
Özvan, Acar

Lienhart, D. A., 1994. Durability issues in the production of rock for erosion control. In: Proceedings of the 1st North American rock Mechanics symposium on rock mechanics, models, and measurements, challenges from industry, Austin, Balkema, Rotterdam, 1083-1090.

Lienhart, D. A., 1998. Rock engineering rating system for assessing the suitability of armourstone sources, Advances in Aggregates and Armourstone Evaluation. The Geological Society, Engineering Geology Special Publication, 13, 91-106.

Özden, U. A., Topal, T., 2009. Evaluation of andesite source as armourstone for a rubble mound breakwater (Hisarönü-Turkey). Environmental Earth Sciences, 59 (1), 39-49.

Özvan, A., Dinçer, İ., Acar, A., 2011. Quality assessment of Geo-Material for coastal structures (Yumurtalık-Turkey). Marine Georesources and Geotechnology, 29 (4), 299-316.

Parlak, O., Kozlu, H., Demirkol, C., Delaloye, M., 1997. Intracontinental Plio-Quaternary Volcanism Along The African-Anatolian Plate Boundary, southern Turkey. Ofioliti, 22 (4), 111117.

Parlak, O., Delaloye, M., Kozlu, H., Fontignie, D., 2000. Trace element adn Sr-Nd isotope geochemistry of the alkali basalt observed along the Yumurtalık Fault (Adana) in Turkey. Yerbilimleri, 22, 137-148.

Pelen, N., 1995. Osmaniye-Dörtyol-Erzin yöresi Kuvaterner bazaltlarının jeolojisi, petrografisi ve hidrojeolojik özellikleri. Çukurova Üniversitesi Fen Bilimleri Enstitüsü Yüksek Lisans Tezi, 144 $\mathrm{s}$, (yayınlanmamış).
Robertson, A., Unlügenç, U. C., İnan, N., Tasli, K., 2004. The Misis - Andırın Complex: a Mid Tertiary melange related to late-stage subduction of the Southern Neotethys in S Turkey. Journal of Asian Sciences, 22, 413-453.

Sevdinli, G., 2005. Ceyhan (Adana) dolayı yapıtaşı potansiyelinin değerlendirilmesi. Çukurova Üniversitesi Fen Bilimleri Enstitüsü Yüksek Lisans Tezi, 134 s, (yayınlanmamış).

Smith, M. R. (Ed.), 1999. Stone: Building Stone, Rock Fill and Armourstone in Construction. Engineering Geology Group Special Publication, vol. 161. Geological Society, London, 478 p.

TS 699, 1987. Tabi yapıtaşları muayene ve deney metotları. TSE, Ankara, $84 \mathrm{~s}$.

TS EN 1367-1, 2001. Agregaların termal ve bozunma özellikleri için deneyler-bölüm 1: donma ve çözünmeye karşı direncin tayini. TSE, Ankara, 11 s.

TS EN 933-9, 2001, İnce Agregalarda Metilen Mavisi Değerinin Tayini. TSE, Ankara.

TS EN 13383-1, 2004a. Koruma tabakası taşları (zırh taşı) - Bölüm 1: Özellikler. TSE, Ankara.

TS EN 13383-2, 2004b. Koruma tabakası taşları (zırh taşı) - Bölüm 1: Deney Metotları. TSE, Ankara.

Topal, T., Acrr, O., 2004. Quality assessment of armourstone for a rouble mound breakwaters (SinopTurkey). Environmental Geology, 46, 905-913.

Uysal, G., 2005. İsalı - Doruk - Yumurtalık civar1nın (Adana) tektono-stratigrafisi. Çukurova Üniversitesi Fen Bilimleri Enstitüsü Yüksek Lisans Tezi, 78 s, (yayınlanmamış). 
Yurtmen, S., Rowbotham, G., İşler, F., Floyd, P.A., 2000. Petrogenesis of basalts from Southern Turkey: The Plio-Quaternary volcanism to the North of İskenderun Gulf. Tectonics and Magmatism in Turkey and the Surrounding Area. Geological Society, London, special Publications, 173, 489-512.

Yurtmen, S., Gullou, H., Westaway, R., Rowbotham, G., Tatar, O., 2002. Rate of strike-slip motion on the Amonos Fault (karasu Valley, southern Turkey) constrained by K-Ar dating and geochemical analysis of Quaternary basalts. Tectonophysics, 344, 207-246.

Yüce, G., 2001. Hatay-Erzin (Yeşilkent) Ovası ve Burnaz Kaynağının Hidrojeolojik Özellikleri. Jeoloji Mühendisliği Dergisi, 25 (2), 21-46. 